\title{
A Quantitative Model for the Regulation of Naturally Occurring Cell Death in the Developing Vertebrate Nervous System
}

\author{
Lucia Galli-Resta' and Giovanni Resta ${ }^{2}$ \\ 'Istituto di Neurofisiologia CNR, 56127 Pisa, Italy and 'Istituto di Elaborazione dell'Informazione CNR-I.E.I., 56100 Pisa, Italy
}

\begin{abstract}
Throughout the animal kingdom, the formation of the nervous system involves the elimination of many cells soon after their generation. This phenomenon, known as naturally occurring cell death, has precise time schedules and is observed in the vast majority of neural structures. It causes the loss of $15-85 \%$ of the neurons generated.

Manipulations of the target structure can considerably affect the amount of cell death in a nervous center, but the regulation of this process is still controversial. While in some experiments cell death leads to a linear relationship between the size of the target and that of the input, other experiments show dramatic deviations from a linear prediction.

It is quite possible that cell death is regulated by different mechanisms in different cases and that the search for a single explanation would be doomed to failure. However, it is shown here that if mutual trophic interactions are assumed to occur between connected structures, a general model can be developed for the regulation of histogenetic cell death in the developing nervous system of vertebrates. The model relies on few assumptions, all derived from a number of experimental studies. Cells destined to form a neural center are generated according to a program and die around a certain age unless a trophic factor is supplied that prevents their death. Target cells exert a trophic influence on input cells and vice versa.
\end{abstract}

The model quantitatively describes the time course and the amount of cell death in neural structures, thereby reconciling in a unitary framework experimental findings that until now have appeared conflicting.

Naturally occurring cell death has been observed in nearly all centers of the developing vertebrate nervous system (for a review, see Oppenheim, 1981, 1991). Around the end of the cell generation period, when cells are already contacting their target, between $15 \%$ and $85 \%$ of the neurons rapidly degenerate according to precise time schedules.

Following cell death, a linear relationship between the adult number of afferent neurons and the size of their target is found in a variety of neural structures (Shorey, 1909; Hamburger, 1934; Laing, 1982; McLennan, 1982; Habgood et al., 1984; O'Leary and Cowan, 1984; Tanaka and Landmesser, 1986; Herrup and Sunter, 1987; Lanser and Fallon, 1987; Lamb et al.,

\footnotetext{
Received Oct, 4, 1991; revised Apr. 17, 1992; accepted June 9, 1992.

We thank Profs. A. Fiorentini, D. Burr, and L. Maffei for helpful comments.

Correspondence should be addressed to Dr. Lucia Galli-Resta, Istituto di Neurolisiologia, CNK, via S. Zeno 51, 56127 Pisa, Italy.

Copyright (c) 1992 Society for Neuroscience $0270-6474 / 92 / 124586-09 \$ 05.00 / 0$
}

1989; see also Oppenheim, 1981, and references within). These observations have lead to the suggestion that naturally occurring cell death serves to match in size interconnected neural populations, and that some factor proportional to the target size may regulate cell death in the input structure. This factor is most likely to be a trophic substance for input cells (for a review, see Levi Montalcini, 1987; Walicke, 1989; Thoenen, 1991). Some experiments strongly contradict this hypothesis of size matching. In the developing Xenopus, if motoneurons from both sides are forced to innervate a single limb early in development, the number of motoneurons surviving cell death is close to normal (Lamb, 1980; Lamb et al., 1989). The size-matching hypothesis would instead predict the final population on each side to be reduced to half the normal value since the two pools of motoneurons share a single target. Transplantation of a supranumerary target before the onset of cell death induces only a very limited increase in the number of surviving afferent neurons (Hollyday and Hamburger, 1976; Boydston and Sohal, 1979), rather than saving double the normal number of cells, as the size-matching hypothesis would predict. Finally, in the developing mammalian nervous system, enucleation of one eye during the period in which each side of the brain receives intermingled projections from both retinas leaves the remaining eye with twice its normal target but induces only a very limited increase in the number of retinal ganglion cells surviving cell death in the remaining eye (Rakic and Riley, 1983; Williams et al., 1983; Sretavan and Shatz, 1986). Paradoxically, if the experiment is performed early enough, less cells than normal project to the "freed" ipsilateral side of the brain (Godement et al., 1987).

In the attempt to reconcile the seemingly contrasting results, we have developed a theoretical model that predicts quantitatively the amount and time course of cell death in developing neural structures. The conceptual core of the model is to consider trophic interactions to be mutual, so that trophic factors are supplied by the target cells to the afferent neurons, and mutually input cells exert a trophic action on the cells that they innervate. Trophic interactions in the anterograde direction, where the input is crucial for target development and survival, are well known. Examples are muscular atrophy following denervation and the degeneration observed in neural structures deprived of their input during development (see Purves, 1988; Oppenheim, 1991; and references within the two). We show here that by considering the trophic effects of input cells on the target together with target-derived trophic effects, it is possible to reconcile the conflicting findings concerning the regulation of cell death.

A preliminary account of the model has been presented previously (Galli-Resta and Resta, 1991). 


\section{The Model}

The model relies on four assumptions derived from a number of experimental studies.

First, we assume that cells in each nervous structure are generated with a precise time schedule. This is the general pattern of cell genesis that has been observed (for a review, see Jacobson, 1991). First a few cells are generated, then more cells are added every day, and finally the rate of cell generation declines. The span of life in which cells are generated and the maximum number of cells observed in a neural structure are peculiar to each structure and vary very little from animal to animal in the same species.

The second hypothesis is that generated cells normally die around a certain time after their generation unless a trophic factor saves them. It is experimentally observed that for each neural population the interval of time during which cell death naturally occurs and the number of cells that die are fixed.

The third hypothesis is that the trophic factor that prevents neuronal death is supplied by the target cells.

The fourth hypothesis is that mirror events take place in the target, its cells being destined to die unless they are saved by trophic factors, supplied at least partly by the input.

Formalizing these assumptions, we derive a simple system of differential equations. For simplicity, we start with just two interacting structures, 1 and 2, with structure 1 innervating structure 2. The two structures are assumed to have no other connections. Solutions of the system will be the two functions of time $N_{1}$ and $N_{2} . N_{1}$ is the number of cells of structure 1 innervating structure $2 ; N_{2}$, the number of cells in structure 2 .

Cells are generated according to a precise time schedule. At first a few cells begin to appear, then more and more cells, and then finally cell genesis slows down and stops. The rate of genesis will be modeled by a Gaussian function, which fits well many published time curves of cell genesis rate (see, e.g., Young, 1985). The rate of genesis is given by

$$
\frac{d N_{1}}{d t}=\frac{A_{1}}{\sqrt{2 \pi} \sigma_{1}} e^{-(1 / 2)\left(\left(t-T_{1}\right) / \sigma_{1}\right)^{2}}
$$

where $A_{1}$ is the number of cells generated in structure 1 sending projections to structure $2, T_{1}$ is the center of the interval of cell generation, and $4 \sigma_{1}$ is the width of the interval of cell generation (Fig. 1A).

According to the second hypothesis, cells die after a certain interval. Death occurs around a certain fixed age $D_{1}$ peculiar to the structure. The probability for a cell to die around this time is again assumed to be Gaussian of time constant $\rho_{1}$. If only the two above factors were to contribute to the variation of cell number, the equation would be

$$
\frac{d N_{1}}{d t}=\frac{A_{1}}{\sqrt{2 \pi}}\left[\frac{1}{\sigma_{1}} e^{-(1 / 2)\left(\left(t-T_{1}\right) / \sigma_{1}\right)^{2}}-\frac{1}{\rho_{1}} e^{-(1 / 2)\left(\left(t-D_{1}\right) / \rho_{1}\right)^{2}}\right]
$$

which describes a transient creation of cells all destined to disappear (Fig. 1B). However, trophic factors rescuc somc cclls. We will describe their trophic action by a positive function, $F$, reducing the rate of cell disappearance. Thus, at any given time, the rate of dying cells is

$$
\left(\frac{A_{1}}{\sqrt{2 \pi} \rho_{1}}-F\right) e^{-(1 / 2)\left(\left(t-D_{1}\right) / \rho_{1}\right)^{2}}
$$

For any time $t$, the higher the value of $F$, the more cells survive cell death. We do not know the exact dependence of $F$ on the two variables $N_{1}$ and $N_{2}$. However, nearly all functions can be expressed as Taylor series and it will be shown that using the lowest-order nonzero term of the series provides a good approximation to the problem under investigation. We will here advance the simplifying hypothesis that $F$ depends upon time only through $N_{1}$ and $N_{2}$, which is equivalent to considering an average $F$. The Taylor expansion is therefore

$$
\begin{aligned}
F= & \alpha_{00}+\alpha_{11} N_{1}+\alpha_{12} N_{2}+\alpha_{21} N_{1}^{2} \\
& +\alpha_{22} N_{2}^{2}+\alpha_{23} N_{1} N_{2}+\cdots \cdot
\end{aligned}
$$

$F$ describes the trophic interaction exerted by structure 2 on the cells in structure 1 . If structure 2 does not exist $\left(N_{2}=0\right)$, it cannot provide any trophic factor to structure 1 and $F$ must be zero, independently of $N_{1}$; that is, the constant term $\alpha_{00}$ must be zero and so must be all the coefficients $\alpha_{i j}$ of the terms that are only powers of $N_{1}$. The trophic factor has to be taken up by the cells of structure 1 . If no cells of structure 1 are projecting to structure $2\left(N_{1}=0\right)$, structure 2 cannot exert its trophic influence on structure 1 and $F$ must be zero independently of $N_{2}$. This implies that all the coefficients $\alpha_{i j}$ of the terms that are only powers of $N_{2}$ must be zero. The lowest nonzero term is therefore

$$
F=\alpha N_{1} N_{2} .
$$

The dependence of $F$ on $N_{2}$ could be easily explained. Cells in structure 2 produce the trophic factor that rescues cells in structure 1 from death. The more cells that are in structure 2, the more trophic factor is produced, and the more cells in structure 1 are saved. The dependence of $F$ on $N_{1}$, the number of cells receiving the trophic factor, means that cells can modulate the trophic action exerted on them, as we will discuss later. The first complete equation is (Fig. 1C)

$$
\begin{aligned}
\frac{d N_{1}}{d t}=\frac{A_{1}}{\sqrt{2 \pi}} & {\left[\frac{1}{\sigma_{1}} e^{-(1 / 2)\left(\left(t-T_{1}\right) / \sigma_{1}\right)^{2}}\right.} \\
& \left.-\frac{1}{\rho_{1}}\left(1-\alpha_{12} \frac{N_{1} N_{2}}{A_{1}} \sqrt{2 \pi} \rho_{1}\right) e^{-(1 / 2)\left(\left(t-D_{1}\right) / \rho_{1}\right)^{2}}\right]
\end{aligned}
$$

where the indices of $\alpha_{12}$ now emphasize that it refers to the interaction between structure 1 and structure 2 .

The fourth hypothesis of the model, that trophic interactions are mutual, means that a symmetrical equation can be written for the number of cells in structure 2 , the structure innervated by structure 1 . The evolution in time of cell numbers in the two connected structures 1 and 2 will be described by the solutions of the system of differential equations

$$
\begin{aligned}
\frac{d N_{1}}{d t}=\frac{A_{1}}{\sqrt{2 \pi}} & {\left[\frac{1}{\sigma_{1}} e^{\left.-(1 / 2)\left(t-T_{1}\right) / \sigma_{1}\right)^{2}}\right.} \\
& \left.-\frac{1}{\rho_{1}}\left(1-\alpha_{12} \frac{N_{1} N_{2}}{A_{1}} \sqrt{2 \pi} \rho_{1}\right) e^{-(1 / 2)\left(\left(t-D_{1}\right) / \rho_{1}\right)^{2}}\right], \\
\frac{d N_{2}}{d t}=\frac{A_{2}}{\sqrt{2 \pi}} & {\left[\frac{1}{\sigma_{2}} e^{-(1 / 2)\left(\left(t-T_{2}\right) / \sigma_{2}\right)^{2}}\right.} \\
& \left.-\frac{1}{\rho_{2}}\left(1-\alpha_{21} \frac{N_{1} N_{2}}{A_{2}} \sqrt{2 \pi} \rho_{2}\right) e^{\left.-(1 / 2)\left(t-D_{2}\right) / \rho_{2}\right)^{2}}\right],
\end{aligned}
$$




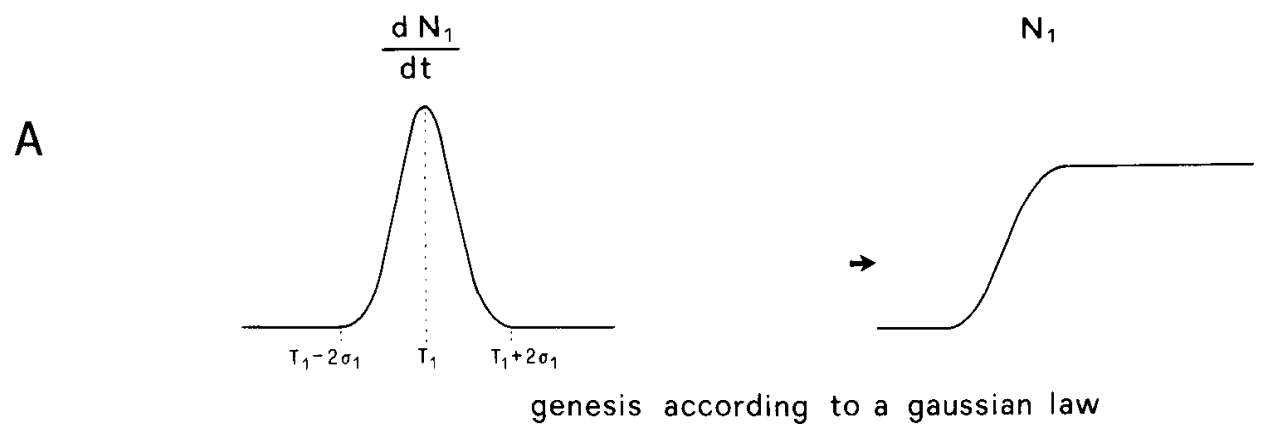

Figure 1. Graphic illustration of the time course of the total number of cells $N_{1}$ in structure 1 as determined by the various terms that constitute the model equations. The left column illustrates the derivative $d N_{1} / d t$; the right column, the function $N_{1} . A$, Rate of genesis according to a Gaussian law (Eq. 1). The interval of cell genesis is centered around $T_{1}$ and lasts $4 \sigma$. With this single contribution, the number of cells $N_{1}$ in the structure rises from zero to a maximum constant value. $B$, Genesis and fate of death after a certain time (Eq. 2). Cell death occurs in a time interval centered on $D_{1}$ and lasting $4 \rho$. With these two contributions, the number of cells $N_{1}$ in the structure rises to a peak value then goes back to zero. $C$, Some of the generated cells are saved by the trophic factor provided by structure 2 (Eq. 6).
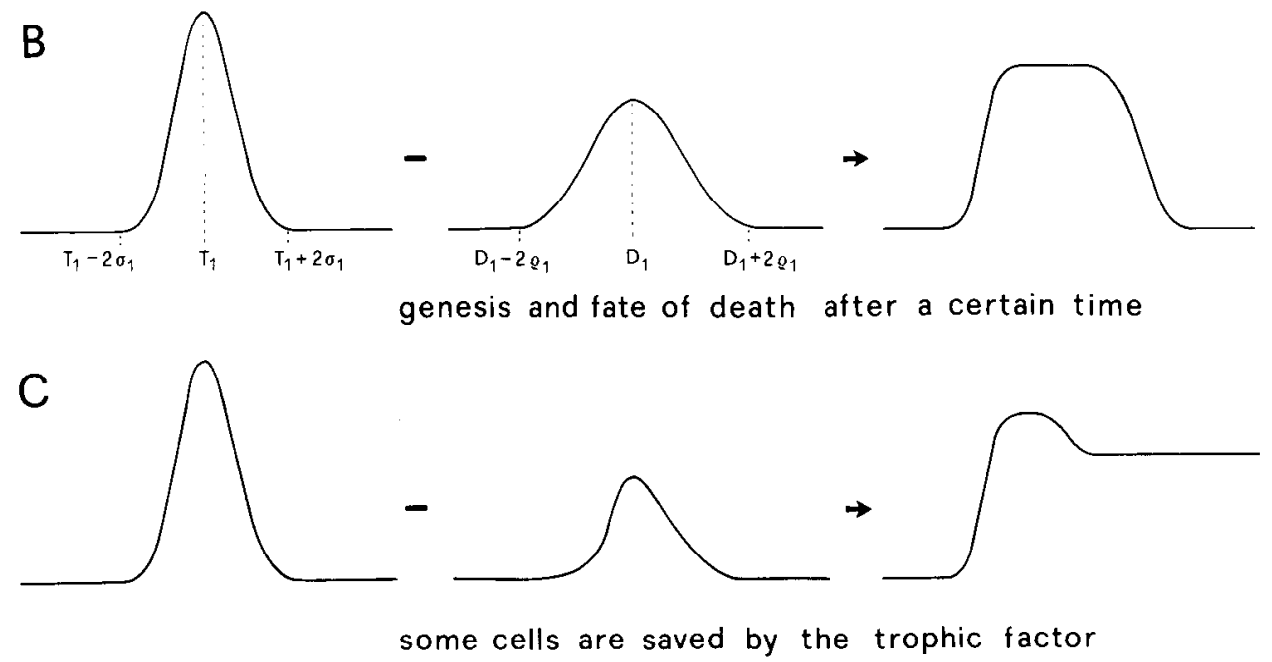

where only the parameters $\alpha_{12}$ and $\alpha_{21}$ can be varied to fit the data best.

If more than two interacting structures are considered, we will have a system of more differential equations of the type

$$
\begin{aligned}
\frac{d N_{i}}{d t}=\frac{A_{i}}{\sqrt{2 \pi}}[ & \frac{1}{\sigma_{i}} e^{-(1 / 2)\left(\left(t-T_{i}\right) / a_{i}\right)^{2}}-\frac{1}{\rho_{i}}\left(1-\frac{\sqrt{2 \pi} \rho_{i}}{A_{i}} \sum_{j} \alpha_{i j} N_{i} N_{j}\right) \\
& \left.\times e^{-(1 / 2)\left(\left(t-D_{i}\right) / \rho_{j}\right)^{2}}\right]
\end{aligned}
$$

where $\alpha_{i j}=0$ when the two structures $i$ and $j$ are not directly connected.

\section{Simulations of experimental studies}

To simulate specific cases, the coefficients $T_{i}, \sigma_{i}, D_{i}, \rho_{i}$, and $A_{i}$ in the equations have been derived from the experimental studies that describe cell genesis and the presence of degenerating cells in the particular neural structure $i$ under consideration. Since $T_{i}$ is the center of the Gaussian curve describing the rate of genesis (Fig. 1 $A$ ), it corresponds to the center of the interval of cell genesis determined by studies dating cell birth, such as autoradiographic experiments with ${ }^{3} \mathrm{H}$-thymidine. According to a Gaussian rate of genesis, $96 \%$ of the cells are born betwecn $T_{i}$ $-2 \sigma_{i}$ and $T_{i}+2 \sigma_{i}$. Therefore, $4 \sigma_{i}$ is assumed to be the width of the interval of cell genesis as determined experimentally. Similarly, $D_{i}$ is the center and $4 \rho_{i}$ the width of the interval during which degenerating cells are observed in structure $i$ (Fig. 1B). $A_{i}$ is the total number of cells generated in $i$. In most structures, cells start to die close to the end of the period of cell generation, which makes the maximum number of cells observed in structure $i$ an estimate of $A_{i}$. This leads to values largely within the experimental errors. Since we are describing interacting structures, when input cells send their projections to the target long after their birth, their genesis curve is correspondingly shifted to the time target cells "see" them arrive. The experimental indetermination that accompanies the coefficients above does not significantly affect the solutions of the system.

In each case, the system was numcrically solved by the use of a Runge-Kutta method (see, for a reference, Froberg, 1966) on an IBM PS/ 2 computer. Only $\alpha_{i j}$ could be varied to fit the experimental curves best. If only two interacting structures are studied, just one parameter per equation is free to vary.

In solving the system, it was imposed that

$$
\left(1-\frac{\sqrt{2 \pi} \rho_{i}}{A_{i}} \sum_{j} \alpha_{i j} N_{i} N_{j}\right) \geq 0,
$$

which means that trophic factors can save generated cells but cannot create new ones.

\section{Results}

Wc present here some simulations of experimental data obtained using the model, with no intention of being exhaustive. As an example of just two interacting structures, we will consider the development of the retinotectal projections of the rat. Between $92 \%$ and $98 \%$ of the adult rat retinal ganglion cells project to the superior colliculus (Sefton and Dreher, 1985). This projection develops when retinal ganglion cells are hardly receiving 
any inputs (Horsburgh and Sefton, 1987). Retinal ganglion cells are generated in the rat in the $7 \mathrm{~d}$ between embryonic day 12 (E12) and E18 (reviewed in Dreher and Robinson, 1988). Therefore, the interval of cell generation, $4 \sigma_{1}$, is $7 \mathrm{~d}$. Degenerating cells are visible in the ganglion cell layer of the retina as early as E17 (L. Galli-Resta, unpublished observation) up to postnatal day 14 (P14; Perry et al., 1983; Horsburgh and Sefton, 1987). In the model equations, we have therefore $D_{1}=\mathrm{P} 4$ and $4 \rho_{1}=$ $19 \mathrm{~d}$. Neurons forming the rat superior colliculus leave the mitotic cycle between E12 and E18 (Mustari et al., 1979), which leads to $T_{2}=$ E15 and $4 \sigma_{2}=7 \mathrm{~d}$. Degenerating cells in the superficial layers of the superior colliculus, where retinal fibers arrive, are seen from P2 to P10 (Giordano et al., 1980), which means $D_{2}=\mathrm{P} 6$ and $4 \rho_{2}=9 \mathrm{~d}$. The first retinal ganglion cells leave the mitotic cycle around E12, but only around E15 are the first axons seen reaching the colliculus (Bunt et al., 1983). Since $N_{1}$ is the retinal ganglion cells that at time $t$ project to the superior colliculus, to obtain $T_{1}$ we have to shift the center of the ganglion cell genesis interval derived by autoradiographic studies to $3 \mathrm{~d}$ later, to make this interval correspond to the times the collicular cells "see" the input arise. This means $T_{1}=$ E18. Solving the system of equations obtained, we tried to fit the experimental curve by Crespo et al. (1985) for the number of axons in the rat optic nerve during development. $\alpha_{12}$ and $\alpha_{21}$ have been varied to fit the data best. The best fit obtained is illustrated in Figure 2, superimposed on the experimental data. The model simulation is within the error bars of all experimental points.

As a second example of how the model can simulate experimental data, we will consider the development of the monkey visual system. Nearly all monkey retinal ganglion cells project to the lateral geniculate nucleus (LGN; see Williams and Rakic, 1988), which in turn projects to the primary visual cortex. At the time when these projections are developing and cell death occurs, few if any synapses are observed on retinal ganglion cells (Nishimura and Rakic, 1985). Thus, retinal ganglion cells are hardly receiving any inputs while sending their projections to the LGN. At this time, LGN neurons are also sending out their axons, but their final target, layer IV of the visual cortex, has still to be generated (Rakic, 1976). LGN fibers wait in close proximity to the subplate neurons, a dense contingent of cells that transiently populate the area below the future cortex (Kostovic and Rakic, 1990). The presence of these cells seems to exert a strong influence on the thalamic afferents, which never reach their target if the subplate cells are destroyed early in development (Ghosh et al., 1990). On the basis of these data, we have modeled the monkey visual system as a three-structure interaction, involving retinal ganglion cells, LGN cells, and the subplate neurons. The best fit obtained is shown as continuous curves superimposed to the experimental data (circles) in Figure 3. Since no data are available for the number of subplate cells, this curve is drawn on an arbitrary ordinate scale and it is only meant to indicate the time interval in which the model predicts the presence of a significant number of subplate neurons. This corresponds to what is experimentally observed (Kostovic and Rakic, 1990).

\section{Reconciling conflicting experiments}

The most attractive feature of the model is that it reconciles a number of experimental findings that appear to conflict with each other. Many experiments point to a linear relationship between the final sizes of interconnected structures. If the target

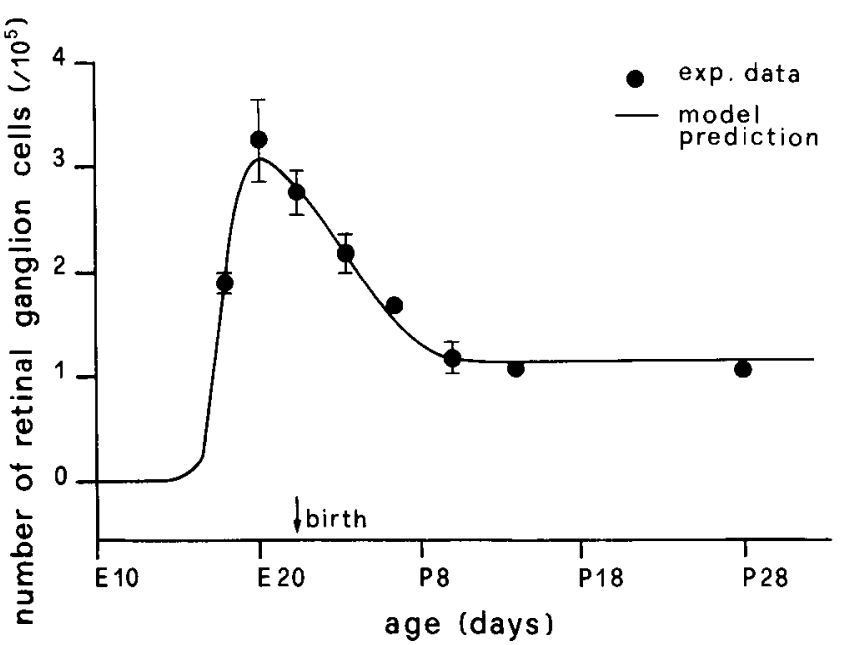

Figure 2. Development of the retinotectal projections in the rat. The time coursc of the number of retinal ganglion cells obtained running the model for $\alpha_{12}=0.02$ and $\alpha_{21}=0.025$ is shown as a continuous line superimposed to the experimental data by Crespo et al. (1985) indicated by the solid circles. The model fit is within the error bars of all the experimental points. The equation parameters were derived from a number of studies referred to throughout the text. The model was run in the simplifying hypothesis of a two-structure interaction between retinal ganglion cells and collicular cells. This approximation already provides a good fit.

is reduced in size, the input is proportionally reduced through an appropriate amount of cell death (Hamburger, 1934; Sohal and Narayanan, 1975; O'Leary and Cowan, 1984; Tanaka and Landmesser, 1986; Herrup and Sunter, 1987; Lanser and Fallon, 1987; Lamb et al., 1989). However, another set of apparently similar experiments has given results that strongly deviate from this linear relation, challenging the size-matching hypothesis (Hollyday and Hamburger, 1976; Boydston and Sohal, 1979; Lamb, 1980; Rakic and Riley, 1983; Williams et al., 1983; Sretavan and Shatz, 1986; Godement et al., 1987). The model we propose predicts the outcome of both kinds of experiments.

A clear-cut linear relationship between input and target final size was found in the case of cerebellar mouse chimeras studied by Herrup and Sunter (1987). Chimeras were created between a wild-type mouse and a mutant (Staggerer). In the Staggerer mutant, no normal Purkinje cells develop (Herrup and Mullen, 1979), and granule cells that are normally generated degenerate later for lack of appropriate target. Chimeras created by the fusion of Staggerer and wild-type eight-cell embryos develop into mice with either a lower or an equal to normal number of normal Purkinje cells. In each chimeric brain, a number of granule cells linearly related to the number of normal Purkinje cells survive to adulthood. In our simulation of the cxpcriment, structure 1 comprises the Purkinje cells and structure 2 the granule cells. The coefficients used to fit the curve for the wildtype animal were obtained from the experimental data relating to the generation of Purkinje and granule cells and to their connections and degeneration (reviewed in Jacobson, 1991). If $A_{1}=A$ is the number of normal Purkinje cells generated in a wild-type animal, we simulate the chimeras choosing $A_{1}<A$ (less normal Purkinje cells are generated than in the wild-type). Every other parameter is the same as in the simulation of the normal, wild-type animal. Running the model for different values of $A_{1}$, we can plot in each case the number of normal Purkinje 


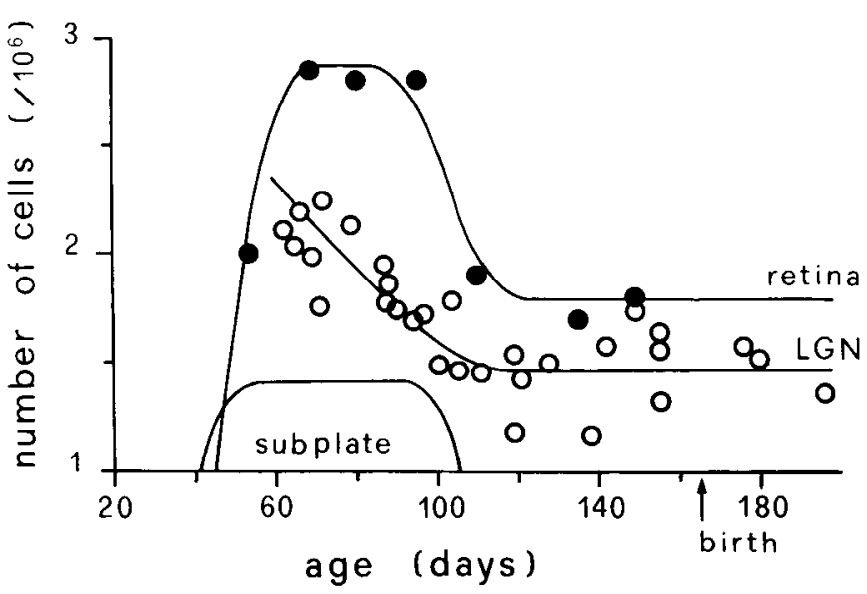

Figure 3. Development of the monkey visual system. The model's best simulation of the time course of the number of retinal ganglion cells and LGN neurons is illustrated as continuous lines. The experimental data are shown for comparison. Solid circles represent the number of retinal ganglion cells found at different ages in the study by Rakic and Riley (1983). Open circles are the number of LGN neurons reported at different ages in the study by Williams and Rakic (1988). Since no data exist as to the number of subplate neurons, the model simulation curve for these cells is drawn without an ordinate scale. It is only intended to show the period of transient presence of a dense population of subplate cells as predicted by the model. This corresponds to the period in which these neurons are experimentally observed in significant amounts (Kostovic and Rakic, 1990). The model simulation was run as a threestructure interaction. The equation coefficients were derived from Rakic (1977), Rakic and Riley (1983), Dreher and Robinson (1988), Williams and Rakic (1988), and Kostovic and Rakic (1990). The curves shown were obtained for $\alpha_{12}=0.0204, \alpha_{21}=0.0085, \alpha_{23} A_{3}=0.006$, and $\alpha_{32} A_{3}$ $=0.0006$.

cells against the number of granule cells that survive. A strict linear relationship is obtained, as seen in Figure 4. This straight line coincides with the experimental data regression line.

In accordance with experimental data, the model predicts a strict linear relationship between input and target final size in cases where the target had been surgically reduced before afferent cell death (Hamburger, 1934; Sohal and Narayanan, 1975; Clarke et al., 1976) or was reduced as a consequence of a mutation, as found for the Wingless chick (Lanser and Fallon, 1987).

Turning to experiments where strong deviations from a linear relation between target and input size are reported, we simulate the major result disputing the size-matching hypothesis. If the pools of motoneurons on the two sides of the cord of a developing Xenopus are forced to innervate a single limb before cell death, the final number of adult motoneurons is not significantly different from normal (Lamb, 1980). The size-matching hypothesis would instead predict that the two pools of motoneurons, having to share the same target, and having therefore half their normal target, should be reduced after cell death to half their normal size. If the core hypothesis of the model is accepted, that there exists a continuous mutual interaction between input and target cells, the conflict is resolved. Forcing the motoneurons from both sides to innervate a single limb makes the limb interact with twice the normal input. This will have a higher trophic effect on the limb, which will consequently be reflected as a positive feedback on the motoneurons themselves. Therefore, more than half the normal number of cells will survive in each motoneuron pool. Indeed, the model predicts that a num-

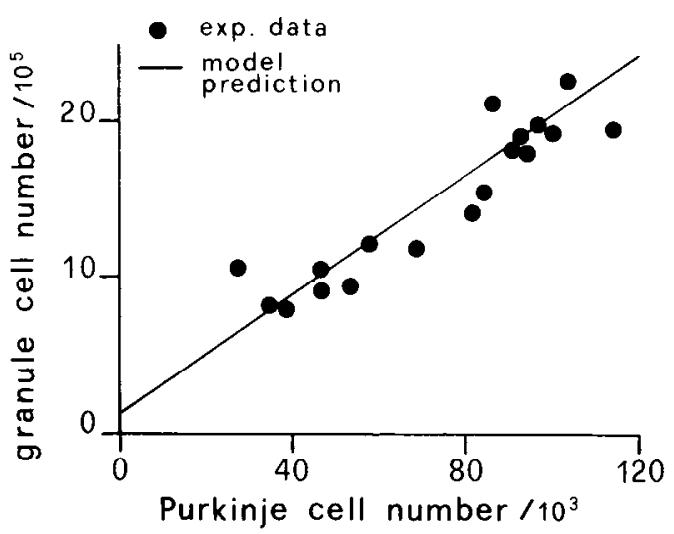

Figure 4. Number of cerebellar granule cells versus the number of normal Purkinje cells in wild-type/Staggerer chimeras. Wild-type/Staggerer chimeras have a variable, lower than normal number of normal Purkinje cells. Herrup and Sunter (1987) found that in each chimera, the number of granule cells that survive cell death is linearly related to the number of normal Purkinje cells found in the animal. In agreement with the experimental data, a strict linear relationship is predicted by the model. The experimental data are shown as solid circles; the model prediction is the continuous straight line. The model simulations of the chimeras were obtained using the same equation coefficients used to fit the data of the normal wild-type case, with the exception of the total number of normal Purkinje cells $\left(A_{1}\right)$, which was assumed to be lower than normal in each chimera. Different chimeras were simulated as programmed with a different reduction in the total number of normal Purkinje cells. The equation coefficients were derived from the studies of cerebellar cell birth, formation of connections, and time of degeneration referred to in Jacobson (1991).

ber of cells close to normal survives in each motoneurons pool, the number being a function of the time when the manipulation is performed (Fig. 5).

Similar reasoning explains why the model predicts, in accordance with experimental studies, that after enucleation of one eye (Rakic and Riley, 1983; Williams et al., 1983; Sretavan and Shatz, 1986; Godement et al., 1987) or after transplantation of a supranumerary target (Hamburger, 1939; Hollyday and Hamburger, 1976; Boydston and Sohal, 1979), less than double the normal number of cells survive cell death, although the target size is doubled by the manipulation. Indecd, in all thesc cases the target is subjected to a lower than normal trophic influence by the reduced input, and this is then negatively reflected back on the input. The earlier these manipulations are performed, the bigger can be the deviation from a linear prediction.

To conclude this illustration of the model, we will simulate the results of an experiment that is usually referred to as being an equivalent of Lamb's experiment, but leads to contrasting results, supporting the size-matching hypothesis. In the avian visual system, each eye receives a centrifugal projection from the contralateral isthmo-optic nucleus (ION). If one eye is enucleated early in development, before the visual connections are formed, both IONs develop projections to the remaining eye. In contrast to Lamb's results, the total number of neurons surviving cell death in both IONs after enucleation never exceeds the number of neurons found in a normal mature ION: the two nuclei are strongly reduced by the carly cnucleation (Clarke et al., 1976; O'Leary and Cowan, 1984). In the light of the model hypotheses, this case is not equivalent to Lamb's. Indeed, in avians, the main projection from the eye goes to the optic tec- 

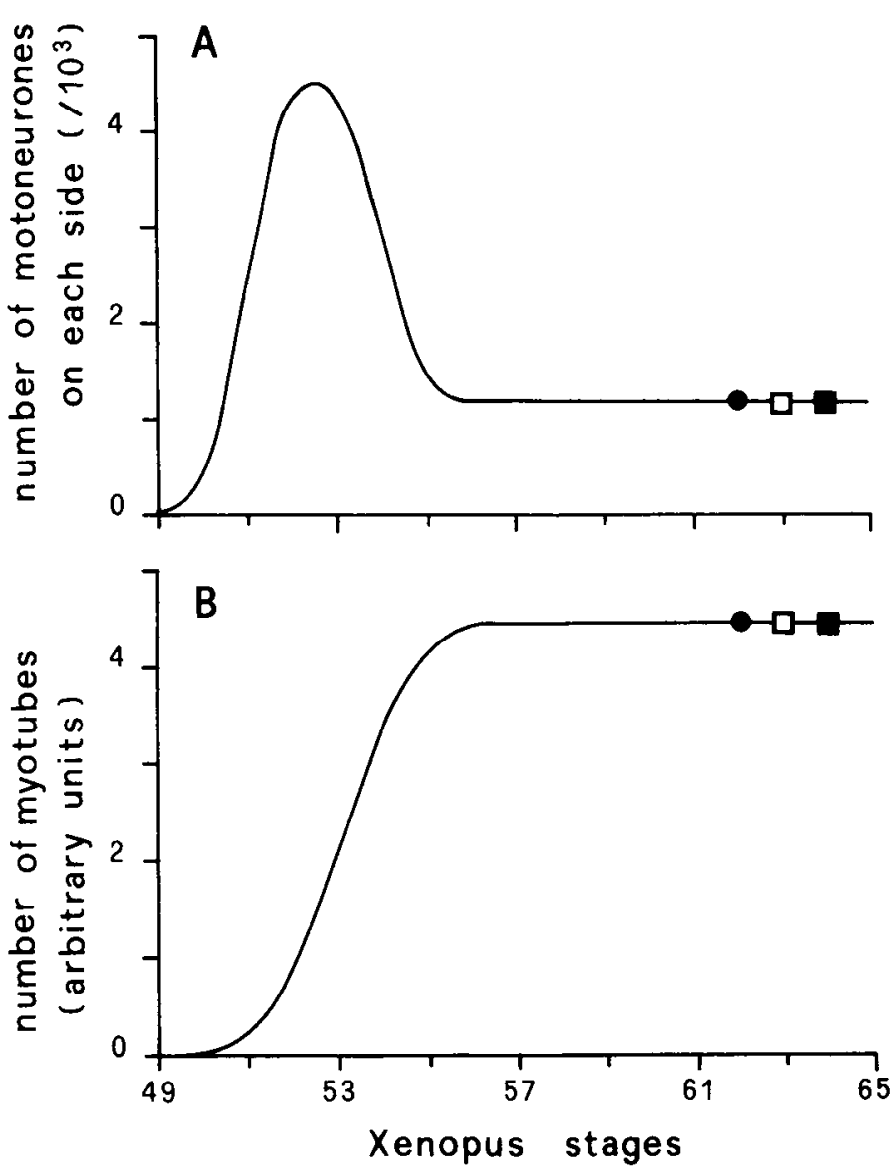

Figure 5. Forcing the motoneurons on both sides of the cord to innervate a single limb in Xenopus does not reduce the final number of motoneurons surviving cell death. $A$, Model simulation of the time course of the number of limb motoneurons on each side of the cord in a normal Xenopus (continuous line). If motoneurons from both sides of the cord are forced to innervate a single limb early in development, it is found experimentally that a number of motoneurons close to normal survive to adulthood on both sides (Lamb, 1980; Lamb et al., 1989). The simulation of this experiment was obtained running the model for the interaction between the two pools of motoneurons with a single leg from the time of the manipulation onward. The initial conditions are the number of motoneurons and the limb size at the times of the manipulation predicted by the model for the normal case of one pool of motoneurons interacting with one leg. The predicted adult numbers of motoneurons in each pool are shown for three cases, corresponding to performing the experimental manipulation on stage 49 (solid circle), stage 50.5 (open square), and stage 52 (solid square). The model predicts that the final number of motoneurons is nearly unaltered by the manipulation. $B$, Development of the limb as predicted by the model in the normal case. Superimposed are the values predicted in the three simulations of Lamb's experiment. No significant variation in the size of the limb is expected as it is experimentally observed (Lamb, 1980; Lamb et al., 1989). The equation coefficients are from Prestige and Wilson (1972) and Prestige (1973). $\alpha_{12} A_{2}=0.495 ; \alpha_{21} A_{2}=1.98$. The model is run as interaction between the motoneurons and the leg. Sensory afferents are not considered since they form their connections later.

tum, which feeds the ION, which in turn projects back to the eye. If we consider that trophic interactions are mutual, we must expect the ION to experience a lower than normal trophic action, not only because of the target reduction, but also as a consequence of the effects of enucleation on the tectum, which is an input to the ION. Therefore, the effect of eye enucleation

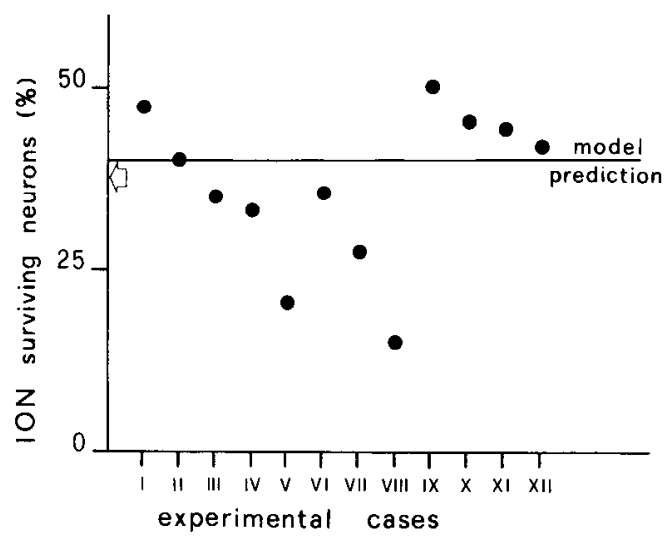

Figure 6. Half or less the normal number of ION neurons survive cell death if one eye is enucleated early in life in avian embryos. In normal chicken, each eye receives projection from the contralateral ION and sends projections to the contralateral tectum. If one eye is enucleated early in development, both ION nuclei send projections to the only remaining eye. This could be looked at as an equivalent of Lamb's experiment. After eye enucleation in chick, however, a variable number of cells survive cell death in the ION nuclei, never exceeding the number of cells found in a single normal ION nucleus. This seems in strong contrast with the results obtained in Lamb's experiment. However, if we consider the hypothesis of mutual trophic interaction between connected structures, the two experiments are conceptually different. ION cells project to the eye and receive input from the optic tectum, to which the eye projects. Therefore, eye enucleation affects the survival of ION cells both because these cells are deprived of part of their output, and also through its effects on tectal cells, input to the ION. More severe effects on ION cells survival are to be expected than those observed on the motoneurons in Lamb's experiment. The figure illustrates the total number of ION neurons (adding neurons from the ipsi- and the contralateral ION) projecting to the remaining retina after early enucleation found in each of the 12 experimental cases described by O'Leary and Cowan (1984). The number is expressed as a percentage of the total number of ION neurons (adding neurons from the ipsi- and the contralateral ION) found in the normal cases. The arrow indicates the average number of surviving neurons found experimentally. The straight horizontal line is the average model prediction. To run the model simulation of the ION experiment, we first simulated the normal case using data from LaVail and Cowan (1971), Cantino and Sisto Daneo (1972), Clarke et al. (1976), Rager and Rager (1978), and Dreher and Robinson (1988) to obtain the equation coefficients. The enucleation experiment was simulated eliminating one eye from the equations at the appropriate time, and assuming that the remaining eye receives projections from both ION nuclei and sends part of its fibers to the ipsilateral tectum, as found experimentally (O'Leary and Cowan, 1984; Thanos and Bonhoeffer, 1984).

on the ION must be more dramatic than one would predict if the eye were merely the ION output. The quantitative simulation of this experiment is shown in Figure 6 superimposed on the experimental data.

\section{Discussion}

The general model of naturally occurring histogenetic cell death here presented points to mutual trophic interactions between input and target cells as the mechanism that regulates cell death in the developing vertebrate nervous system. Besides quantitatively fitting the time curves of cell numbers experimentally observed in developing neural structures, the model predicts the outcome of previous experimental manipulations attempted to investigate the mechanisms that regulate cell death in a variety 
of neural centers. Most importantly, the model offers a dynamic picture of how the same mechanisms can interact to yield the events observed even in apparently contrasting experiments. So far we have been unable to find cases where the model failed to simulate the experimental results. Any new quantitative study of cell death in the developing vertebrate nervous system will constitute an additional test for the model. However, we believe at this stage that more sensitive tests would be provided by experiments designed to verify the hypotheses on which the model relies.

\section{A step-by-step biological translation of the model}

The first of the model hypotheses reflects the evidence that cells destined to form a specific neural population are generated in a limited time window, peculiar to the animal species, with the exception of cells of the olfactory bulb (see Jacobson, 1991).

The second model hypothesis is that generated neurons die around a fixed age unless a trophic factor prevents their death. Cell death is observed throughout the nervous system during development, and it is constrained within a time interval specific for each neural structure. Recent experiments have shown that protein synthesis blockade prevents cell death induced by deprivation of trophic factor in vitro (Martin et al., 1988; Scott and Davies, 1990) as well as naturally occurring cell death in vivo (Oppenheim et al., 1990). This offers a new interpretation of trophic intcractions. Cell death could result from a specific genetic program, requiring new protein synthesis, and trophic factors could act to silence this death program, otherwise destined to be activated in the cell. Invertebrate programmed cell death (Ellis and Horvitz, 1986; Chalfie and Wolinsky, 1990), as well as the degeneration of cells observed in metamorphosis (Schwartz et al., 1990), depends on death programs. The possibility that histogenetic cell death in vertebrates also requires the activation of an endogenous cell program would reflect a phylogenetically constant theme.

Modeling the interaction between two neural structures, we have described the effect of the trophic action of structure 2 through a positive function $F$ reducing the rate of cell death in structure 1. Approximating for simplicity $F$ with its lowest nonzero Taylor term leads it to depend directly on $N_{1}$ and $N_{2}$, the total number of cells in the two neural structures considered. Since cells in structure 2 provide the trophic factor preventing death of cells in structure 1 , the dependence of $F$ on $N_{2}$ may simply reflect the fact that the more cells in structure 2 produce the trophic factor, the more cells survive in structure 1. The dependence of $F$ on $N_{1}$, the total number of cells receiving the trophic factor, corresponds biologically to the possibility that cells can modulate the trophic action exerted on them. To achieve this modulation, the cells either could modify in time their ability to have access to the trophic factor, by adjusting the synthesis and the distribution of their receptors for this agent, or even could regulate the production of the trophic factor that they receive. The hypothesis that limited access to the trophic factor regulates neuronal survival has been formulated by Oppenheim (1989), who illustrates experimental studies supporting it and proposes that neural electrical activity might modulate the access of afferent cells to the trophic factor. At the moment, it is difficult to base on experimental results any attempt to relate more directly the mathematical description of trophic interactions used for the model to Oppenheim's hypothesis. The hypothesis that neurons can modulate the production of the trophic factor that they receive can be discussed more directly in terms of the existing experimental evidence. Studies of trophic factor expression have shown that NGF, brain-derived neurotrophic factor (BDNF), and neurotrophin-3 are developmentally regulated in various brain areas, reaching a peak and then decreasing to adult levels (Maisonpierre et al., 1990). This time course parallels that of the number of afferent cells in most neural regions. Studies focused on specific input-target systems have shown that the amount of trophic factor mRNA is high when the afferent fibers reach their peak number and then both the target trophic factor mRNA and the number of afferent fibers decrease with a closely parallel time course (Davies and Lumsden, 1984; Davies et al., 1987). In the developing cutaneous epithelium, regional differences in the level of NGF mRNA have also been found during the period of afferent cell death, and these differences are correlated to the density of innervation (Harper and Davies, 1990). In a number of adult structures, a positive correlation has been described between the amount of NGF-sensitive sympathetic innervation and the level of NGF (Korsching and Thoenen, 1983) and NGF mRNA production (Shelton and Reichardt, 1984). To determine whether these results reflect a role played by afferent cells in the regulation of trophic factor production in the target, the study of the trophic activity displayed by aneural targets is crucial. Different systems seem to offer different answers to this question. Extracts of aneural cmbryonic muscles can promotc motoncuron survival both in vitro and in vivo, but at lower levels than extracts from normally innervated muscles (Houenou et al., 1991), suggesting that innervation could regulate the set point of trophic factor production in the target. On the contrary, unaltered levels of NGF mRNA are observed during a phase of afferent cell death in the skin of chickens when the neural tube had been removed before innervation (Rohrer et al., 1988). The two systems could behave in totally different ways, or modulatory mechanisms could be present during other phases of afferent cell death in the chicken skin. In the adult nervous system, input activity can modulate NGF and BDNF mRNA production in the target (Gall and Isackson, 1989; Zafra et al., 1990, 1991; Isackson et al., 1991). The fast-growing knowledge in the field of neurotrophic factors will soon provide new tests for this hypothesis. On theoretical grounds, Purves (1980) has already suggested that the possibility that "neurons regulate the target property that they seek" could be required for a solution of the conflict between experiments that support size matching and those that dispute it.

The dependence upon $N_{i}$ of the trophic interaction reflects the modulation to which the process can be subjected, while $\alpha_{i j}$ is the expression of the intrinsic molecular processes that shape and constrain the trophic phenomena. Since for simplicity we took in no explicit account the possible role of glia, extracellular matrix, and other non-neural sources of trophic influences in the regulation of cell death, $\alpha_{i j}$ may include, as an average expression, this contribution.

The main point of the model is the view of continuous trophic interactions between input and target cells. This theme of mutual exchange of substances could be phylogenetically rather old. Indeed, unicellular eukaryotes exchange pheromones to promote contact between cells of different mating types and to develop interconnections (for a review, see Nobili et al., 1987). While protists do so to exchange genetic materials, neural cells could exchange trophic factors to modify their genetic program from death to further development. 
The number of initially generated cells univocally determines the final number of cells

The model here described has one important implication. Once the molecular mechanisms that determine the dynamic of trophic factor production and exchange are established, and so are the molecular events that determine the time course of the genesis and death programs, it is only the initial number of cells generated in the connected structures that determines how many cells will survive to adulthood. According to the model, about $3,660,000$ retinal ganglion cells have to be generated in the human retina to end up with about $1,080,000$ cells in the adult human eye (Provis et al., 1985). If less cells were initially generated, less cells would survive; if more cells were generated, more would survive. Rules for the selective elimination of particular cells in a structure (e.g., the elimination of cells forming erroneous projections) can be easily incorporated in the model, putting these cells at disadvantage in the exchange process.

\section{Competition and cooperation}

The dynamic of the model that constrains the final number of cells on the number of cells initially generated leads to an additional unexpected consequence. In the nervous system of vertebrates, while the total number of dying cells seems to be predetermined, which cells die seems to depend upon the circumstances (see Purves and Lichtman, 1985). It is often stated that neurons are likely to compete for the trophic factor that is supplicd in a limited amount. The model implies the conclusion that given the molecular modalities of interaction, it is only the number of cells initially generated that determines the number of cells surviving cell death. If two cells are initially generated in a structure and according to the laws of interaction just one cell survives, then, if the same structure had initially only one cell, all else being equal, that cell would not survive. According to the model, one cell would exert a lower trophic influence on the target, and would therefore experience a lower trophic effect in return. If the trophic influence exerted on two cells was enough to support only one of the two, the decreased trophic influence exerted in the case of one initial cell will not be enough to support it. In this respect, cells do not compete but rather cooperate in modulating the trophic activity exerted on them. It is true, however, that when only one of two cells survives, this can either be cell 1 or cell 2 . Thus, at the individual level, cells can be seen as competing.

\section{References}

Boydston GR, Sohal GS (1979) Grafting of additional periphery reduces embryonic loss of neurons. Brain Res 178:403-410.

Bunt SM, Lund RD, Land PW (1983) Prenatal development of the optic projection in albino and hooded rats. Dev Brain Res 6:149168.

Cantino D, Sisto Daneo L (1972) Cell death in the developing chick optic tectum. Brain Res 38:13-25.

Chalfie M, Wolinsky E (1990) The identification and suppression of inherited neurodegeneration in Caenorhabditis elegans. Nature 345: $410-416$.

Clarke PGH, Rogers LA, Cowan WM (1976) The time of origin and the pattern of survival of neurons in the isthmo-optic nucleus of the chick. J Comp Neurol 167:125-142.

Crespo D, O'Leary DDM, Cowan WM (1985) Changes in the number of optic nerve fibers during late prenatal and postnatal development in the albino rat. Dev Brain Res 19:129-134.

Davies A, Lumsden A (1984) Relation of target encounter and neu- ronal death to nerve growth factor responsiveness in the developing mouse trigeminal ganglion. J Comp Neurol 223:124-137.

Davies AM, Bandtlow C, Heumann R, Korsching S, Roher H, Thoenen $\mathrm{H}$ (1987) Timing and site of nerve growth factor synthesis in developing skin in relation to innervation and expression of the receptor. Nature 326:353-358.

Dreher B, Robinson SR (1988) Development of the retinofugal pathway in birds and mammals: evidence for a common 'timetable.' Brain Behav Evol 31:369-390.

Ellis HM, Horvitz HR (1986) Genetic control of programmed cell death in the nematode $C$. elegans. Cell 44:817-829.

Froberg CE (1966) Introduction into numerical analysis. London: Addison Wesley.

Gall CM, Isackson PJ (1989) Limbic seizures increase neuronal production of messenger RNA for nerve growth factor. Science 245:758761.

Galli-Resta L, Resta G (1991) A theoretical model of naturally occurring neuronal death in development. Soc Neurosci Abstr 17:1123.

Ghosh A, Antonini A, McCornell SK, Shatz CJ (1990) Requirement for subplate neurons in the formation of thalamocortical connections. Nature 347:179-181.

Giordano DL, Murray M, Cunningham TJ (1980) Naturally occurring neuronal death in the optic layers of the superior colliculus of the postnatal rat. J Neurocytol 9:603-614.

Godement P, Salaun J, Metin C (1987) Fate of uncrossed retinal projections following early enucleation in the mouse. J Comp Neurol 255:97-109.

Habgood MD, Hopkins WG, Slack JR (1984) Muscle size and motor unit survival in mice. J Physiol (Lond) 356:303-314.

Hamburger V (1934) The effect of wing bud extirpation on the development of the central nervous system of chick embryos. J Exp Zool 68:449-494.

Hamburger V (1939) Motor and sensory hyperplasia following limbbud transplantations in chick embryos. Physiol Zool 12:268-284.

Harper S, Davies AM (1990) NGF mRNA expression in developing cutaneous epithelium related to innervation density. Development 110:515-519.

Herrup K, Mullen RJ (1979) Staggerer chimeras: intrinsic nature of Purkinje cells defect and implication for normal cerebellar development. Brain Res 178:443-457.

Herrup K, Sunter K (1987) Numerical matching during cerebellar development: quantitative analysis of granule cell death in Staggerer mouse chimeras. J Neurosci 7:829-836.

Hollyday M, Hamburger V (1976) Reduction of naturally occurring motoneuron loss by enlargement of the periphery. J Comp Neurol 170:311-320.

Horsburgh GM, Sefton AJ (1987) Cellular degeneration and synaptogenesis in the developing retina of the rat. J Comp Neurol 263:553566.

Houenon LJ, McManaman JL, Prevette D, Oppenheim RW (1991) Regulation of putative muscle-derived neurotrophic factors by muscle activity and innervation: in vivo and in vitro studies. J. Neurosci 11 : 2829-2837.

Isackson PJ, Huntsman MM, Murray KD, Gall CM (1991) BDNF mRNA expression is increased in adult forebrain after limbic seizures: temporal pattern of induction distinct from NGF. Neuron 6:937-948.

Jacobson M (1991) Developmental neurobiology, 3d ed. New York: Plenum.

Korsching S, Thoenen H (1983) Nerve growth factor in sympathetic ganglia and corresponding target organs of the rat: correlation with density of sympathetic innervation. Proc Natl Acad Sci USA 80: 3513-3516.

Kostovic I, Rakic P (1990) Developmental history of the transient subplate zone in the visual and somatosensory cortex of the macaque monkey and human brain. J Comp Neurol 297:441-470.

Laing NG (1982) Timing of motoneuron death in the brachial and lumbar regions of the chick embryo. Dev Brain Res 5:181-186.

Lamb AH (1980) Motoneurones counts in Xenopus frogs reared with one bilaterally innervated hind limb. Nature 284:347-350.

Lamb AH, Ferns MJ, Klose K (1989) Peripheral competition in the control of sensory neuron numbers in Xenopus frogs reared with a single bilaterally innervated hindlimb. Dev Brain Res 45:149-153.

Lanser ME, Fallon JF (1987) Development of the brachial lateral motor column in the Wingless mutant chick embryo: motoneuron 
survival under different degrees of peripheral load. J Comp Neurol 261:423-434.

LaVail MM, Cowan WM (1971) The development of the chick optic tectum. II. Autoradiographic studies. Brain Res 28:421-441.

Levi Montalcini R (1987) The nerve growth factor thirty-five years later. ЕMBO J 6:1145-1 154.

Maisonpierre PC, Belluscio L, Friedman B, Alderson RF, Wiegand SJ, Furth ME, Lindsay RM, Yancopoulos GD (1990) NT-3, BDNF and NGF in the developing rat nervous system: parallel as well as reciprocal patterns of expression. Neuron 5:501-509.

Martin DP, Schmidt RE, DiStefano PS, I owry OH, Carter JG, Johnson EM (1988) Inhibitors of protein synthesis and mRNA synthesis prevent neuronal death caused by nerve growth factor deprivation. J Cell Biol 106:829-844.

McLennan IS (1982) Size of motoneurons pool may be related to number of myotubes in developing muscle. Dev Biol 92:263-265.

Mustari MJ, Lund RD, Graubard K (1979) Histogenesis of the superior colliculus of the albino rat: a tritiated thymidine study. Brain Res 164:39-52.

Nishimura Y, Rakic P (1985) Development of the rhesus monkey retina. I. Emergence of the inner plexiform layer and its synapses. $\mathrm{J}$ Comp Neurol 241:420-434.

Nobili R, Luporini P, Esposito F (1987) Compatibility systems in ciliates. In: Invertebrate models: cell receptors and cell communication (Greenberg AH, ed), pp 6-28. Basel: Karger.

O'Leary DDM, Cowan WM (1984) Survival of isthmo-optic neurons after early removal of one eye. Dev Brain Res 12:293-310.

Oppenheim RW (1981) Neuronal cell death and some related regressive phenomena during neurogenesis: a selective historical review and progress report. In: Studies in developmental neurobiology (Cowan WM, ed), pp 74-133. New York: Oxford UP.

Oppenheim RW (1989) The neurotrophic theory and naturally occurring motoneuron death. Trends Neurosci 12:252-255.

Oppenheim RW (1991) Cell death during development of the nervous system. Annu Rev Neurosci 14:453-501.

Oppenheim RW, Prevette D, Tytell M, Homma S (1990) Naturally occurring and induced neuronal death in the chick embryo in vivo requires protein and RNA synthesis: evidence for the role of cell death genes. Dev Biol 138:104-113.

Perry VH, Henderson Z, Linden R (1983) Postnatal changes in retinal ganglion cell and optic axon populations in the pigmented rat. J Comp Neurol 219:356-368.

Prestige MC (1973) Evidence that at least some of the motor nerve cells that die during development have first made peripheral connections. J Comp Neurol 170:123-134.

Prestige MC, Wilson MA (1972) Loss of axons from ventral roots during development. Brain Res 41:467-470.

Provis JM, Van Driel D, Billson FA, Russell P (1985) Human fetal optic nerve: overproduction and elimination of retinal axons during development. J Comp Neurol 238:92-100.

Purves D (1980) Neuronal competition. Nature 287:585-586.

Purves D (1988) Body and brain. A trophic theory of neural connections. Cambridge, MA: Harvard UP.

Purves D, Lichtman JW (1985) Principles of neural development. Sunderland, MA: Sinauer.

Rager G, Rager U (1978) System matching by degeneration. I. A quantitative electron microscopic study of the generation and degen- eration of retinal ganglion cells in the chicken. Exp Brain Res 33:6578.

Rakic $P$ (1976) Prenatal genesis of connections subserving ocular dominance in the rhesus monkey. Nature 261:467-471.

Rakic P (1977) Genesis of the dorsal LGN in the rhesus monkey: site and time of origin, kinetics of proliferation, routes of migration and pattern of distribution of neurons. J Comp Neurol 176:23-52.

Rakic P, Riley KP (1983) Overproduction and elimination of retinal axons in the fetal rhesus monkey. Science 219:141-144.

Rohrer H, Heumann R, Thoenen H (1988) The synthesis of nerve growth factor (NGF) in developing skin is independent of innervation. Dev Biol 128:240-244.

Schwartz D, Kosz L, Kay BK (1990) Gene activation is required for developmentally programmed cell death. Proc Natl Acad Sci USA 87:6594-6598.

Scott SA, Davies AM (1990) Inhibition of protein synthesis prevents cell death in sensory and parasympathetic neurons deprived of neurotrophic factor in vitro. J Neurobiol 21:630-638.

Sefton AJ, Dreher B (1985) Visual system. In: The rat nervous system (G Paxinos, ed), pp 169-221. Sydney: Academic.

Shelton DL, Reichardt LF (1984) Expression of the $\beta$-growth factor gene correlates with the density of sympathetic innervation in effectors organs. Proc Natl Acad Sci USA 81:7951-7955.

Shorey ML (1909) The effect of the destruction of peripheral areas on the differentiation of the neuroblasts. J Exp Zool 7:25-63.

Sohal GS, Narayanan CH (1975) Effects of optic primordium removal on the development of the isthmo-optic nucleus in the duck (Anas platyrhynchos). Exp Neurol 46:521-533.

Sretavan DW, Shatz CJ (1986) Prenatal development of cat retinogeniculate axon arbors in the absence of binocular interactions. $J$ Neurosci 6:990-1003.

Tanaka H, Landmesser LT (1986) Cell death of lumbo-sacral motoneurons in chick, quail and chick-quail chimeras embryos: a test of the quantitative matching hypothesis of neuronal death. J Neurosci 6:2889-2899.

Thanos S, Bonhoeffer F (1984) Development of the transient retinotectal projection in the chick embryo. A numerical fluorescence microscopic analysis. J Comp Neurol 224:407-414.

Thoenen $H$ (1991) The changing scene of neurotrophic factors. Trends Neurosci 14:165-170.

Walicke PA (1989) Novel neurotrophic factors, receptors and oncogencs. Annu Rev Neurosci 12:103-126.

Williams RW, Rakic P (1988) Elimination of neurons from the rhesus monkey's lateral geniculate nucleus during development. J Comp Neurol 272:424-436.

Williams RW, Bastiani MJ, Chalupa LM (1983) Loss of axons in the cat optic nerve following unilateral enucleation: an electromicroscopic analysis. J Neurosci 3:133-144.

Young RW (1985) Cell differentiation in the retina of the mouse. Anat Rec 212:199-205.

Zafra F, Hengerer B, Leibrock J, Thoenen H (1990) Activity dependent regulation of BDNF and NGF mRNA in the rat hippocampus is mediated by non-NMDA glutamate receptors. EMBO J 9:3545-3550.

Zafra F, Castro E, Thoenen H, Lindholm D (1991) Interplay between glutamate and $\gamma$-aminobutyric acid transmitter systems in the physiological regulation of brain-derived neurotrophic factor and nerve growth factor synthesis in hippocampal neurons. Proc Natl Acad Sci USA 88:10037-10041. 